\title{
Microesferas Poliméricas Magnéticas à Base de Estireno e Divinilbenzeno com Morfologia Casca e Núcleo
}

\author{
Washington J. F. Formiga, Ivana L. Mello, Marcos A. S. Costa \\ Laboratório de Química de Polímeros, Instituto de Química, Universidade do Estado do Rio de Janeiro \\ Manoel R. Silva \\ Departamento de Física e Química, Instituto de Ciências, Universidade Federal de Itajubá \\ Marcia G. Oliveira \\ Divisão de Processamento e Caracterização de Materiais, Instituto Nacional de Tecnologia
}

\begin{abstract}
Resumo: Microesferas poliméricas com propriedades magnéticas à base de estireno (STY) e divinilbenzeno (DVB) foram sintetizadas usando a técnica de polimerização em suspensão em duas etapas. Na primeira, foram preparados os núcleos poliméricos à base de STY e DVB e magnetita. Na segunda, os núcleos foram previamente inchados em uma emulsão de STY e DVB e novamente polimerizados para a formação da casca. Foram variados o método de adição da emulsão e o tempo de inchamento. Os materiais obtidos foram caracterizados quanto ao tamanho de partícula por peneiramento, análise termogravimétrica (TGA), microscopia eletrônica de varredura (SEM) e magnetometria de amostra vibrante (VSM). Os métodos avaliados na formação da casca de poli(estireno-co-divinilbenzeno) produziram partículas com diâmetro médio maior do que o núcleo. Este resultado indica a formação de morfologia casca e núcleo. O controle morfológico só foi obtido com as resinas RR48/1 e RR48/3. O método onde a emulsão de estireno e divinilbenzeno foi adicionada em etapa única, seguida de 48 horas de inchamento do núcleo a $10{ }^{\circ} \mathrm{C}(\mathrm{RR} 48 / 1)$, forneceu o maior rendimento (64\%). Além disso, todas as resinas casca-núcleo foram sensíveis ao estímulo magnético realizado por um ímã, atestando assim que foram produzidas resinas com propriedades magnéticas.
\end{abstract}

Palavras-chave: Copolímero, estireno-co-divinilbenzeno, casca e núcleo, polimerização em suspensão, magnetita.

\section{Magnetic Polymeric Microspheres Based on Styrene and Divinylbenzene with Core-Shell Morphology}

Abstract: Magnetic polymeric microspheres based on styrene (STY) and divinylbenzene (DVB) were synthesized in two steps. Firstly, the polymeric core, constituted by STY, DVB and magnetite, was prepared by suspension polymerization. Then, the core was swollen in a STY and DVB emulsion. Subsequently, a second suspension polymerization was carried out in order to form a shell. The emulsion addition method and the swelling time were varied. The particle size, morphology, thermal stability and magnetic properties of the microspheres were studied by sieving, thermogravimetric analysis (TGA), scanning electron microscopy (SEM) and vibrating sample magnetometry (VSM). All methods tested to forming the poly(styrene-co-divinylbenzene) shell have produced particles with diameter larger than the core. This result indicates the formation of core-shell morphology. The morphologic control was only obtained with resins RR48/1 and RR48/3. Moreover, the method where the emulsion of styrene and divinylbenzene was added in one step, followed by 48 hours of core swelling at $10{ }^{\circ} \mathrm{C}(\mathrm{RR} 48 / 1)$, gave the highest yield (64\%). All microspheres were susceptible to a magnet.

Keywords: Copolymer, styrene-co-divinylbenzene, core-shell, suspension polymerization, magnetite.

\section{Introdução}

Resinas (microesferas) poliméricas com morfologia casca e núcleo vêm sendo amplamente desenvolvidas nos últimos anos, em função de permitirem a combinação de diferentes materiais formadores da casca e do núcleo ${ }^{[1-3]}$. Tais materiais combinam propriedades químicas e físicas distintas, o que gera um produto final com características únicas. O material utilizado para a formação da casca e do núcleo pode ser ambos constituídos de material polimérico, ambos de material inorgânico ou mistos. Em sua grande maioria a casca é de origem polimérica (poliestireno, poliacrilatos, poliacroleína, poli(álcool vinílico), poli(metacrilato de metila), poliaminas, poliminas, poli(etileno glicol), dextran, etc.), ou seja, material inerte que irá impedir o contato direto do núcleo com um possível meio externo, protegendo assim as suas propriedades magnéticas ${ }^{[4]}$.

Diversos trabalhos que tratam da síntese de resinas à base de poliestireno com morfologia casca-núcleo, sem propriedades magnéticas ${ }^{[1,5]}$. Neves ${ }^{[6]}$, sintetizou núcleos de poliestireno por meio da técnica de polimerização em semi-suspensão, os quais foram, posteriormente, inchados na presença dos monômeros estireno e divinibenzeno por cerca de 40 horas e, a seguir, copolimerizados por 10 horas. O resultado final foi a obtenção de microesferas do tipo casca-núcleo usadas como recheio de colunas cromatográficas.

Gonçalves et al. ${ }^{[5]}$, no intuito de melhorar a resistência do poliestireno a solventes, desenvolveram um material que apresentou núcleo de poliestireno e casca constituída de poli(metacrilato de metila). Numa primeira etapa, os núcleos de poliestireno foram obtidos por meio de polimerização em suspensão. Em seguida, uma nova polimerização em suspensão foi iniciada, na presença dos núcleos, com o monômero metacrilato de metila e o iniciador, obtendo-se então, como produto final, microesferas com morfologia casca-núcleo.

A preparação de microesferas poliméricas com morfologia casca-núcleo e propriedades magnéticas também tem sido relatada na literatura ${ }^{[7-9]}$.

Autor para correspondência: Marcos A. S. Costa, Instituto de Química, Universidade do Estado do Rio de Janeiro - UERJ, Rua São Francisco Xavier, 524, Maracanã, PHLC, CEP 20550-900, Rio de Janeiro, RJ, Brasil, e-mail: marcoscosta.iq.uerj@gmail.com 
Duas diferentes resinas poliméricas à base de poli(estirenoco-divinilbenzeno), com e sem propriedades magnéticas, foram sintetizadas através do processo de polimerização em suspensão seguido por sulfonação com ácido sulfúrico. Cada partícula de resina magnética consistia de um único núcleo esférico de aço inoxidável magnético com uma casca de poli(estireno-co-divinilbenzeno) sulfonado $^{[10]}$. Experimentos de adsorção de aminoácidos foram realizadas a fim de estudar a eficácia de ambos os tipos de partículas como trocadores de íons. Os autores verificaram que a adsorção de aminoácidos sobre a resina magnética foi possível, demonstrando a sua utilidade em muitas aplicações potenciais.

Gervald et al. ${ }^{[9]}$ sintetizaram resinas compostas de um núcleo orgânico (poliestireno) coberto por uma camada magnética de nanopartículas de óxido de ferro (ferritas) e uma casca de poliestireno. As partículas poliméricas sintetizadas apresentaram diâmetros médios em torno de $4 \mu \mathrm{m}$, com uma larga distribuição de tamanho, superfície rugosa e um baixo teor de ferrita em sua superfície.

Furusawa et al. ${ }^{[1]}$ sintetizaram um polímero com morfologia casca-núcleo com propriedades magnéticas. Partículas de carga positiva de um material magnético em pó ( $\left.\mathrm{NiO} . \mathrm{ZnO} . \mathrm{Fe}_{2} \mathrm{O}_{3}\right)$ de $20 \mathrm{~nm}$ de diâmetro foram adsorvidas sobre a superfície de microesferas de poliestireno carregadas negativamente (contendo grupo sulfônico ou carboxílico em sua superfície). Para impedir a liberação do óxido e permitir a interação do polímero com biomoléculas, as microesferas poliméricas contendo nanopartículas inorgânicas adsorvidas foram cobertas por uma camada de polímero (poliestireno). Neste processo, o diâmetro da partícula final foi controlado a partir das dimensões do núcleo.

Apesar de a literatura apresentar diversos estudos sobre polímeros com propriedades magnéticas e morfologia cascanúcleo à base de estireno, não foi encontrada até então, uma partícula sintetizada por meio de síntese realizada em duas etapas (síntese do núcleo magnético através de polimerização em suspensão, seguida pelo inchamento destes núcleos em uma emulsão composta pelos monômeros que constituirão a casca). Assim, o presente trabalho visou à síntese e caracterização de partículas poliméricas com morfologia casca-núcleo (core-shell) e propriedades superparamagnéticas, em duas etapas, através do processo de polimerização em suspensão. $\mathrm{O}$ núcleo foi composto por poli(estireno-co-divinilbenzeno) e magnetita, e a casca de poli(estireno-co-divinilbenzeno).

\section{Experimental}

\section{Materiais}

Estireno (grau comercial) foi cedido por cortesia pela Petroflex Indústria e Comércio Ltda (atual Lanxess) e usado como recebido. Divinilbenzeno (grau de pureza de $80 \%$ ) foi adquirido da Aldrich e usado como recebido. Peróxido de benzoíla (grau PA) foi adquirido da Vetec Química Fina Ltda. e usado como recebido. Poli(álcool vinílico) (grau de hidrólise de $85 \%$ e PM $=80.000$ - 125.000) foi adquirido da Air Products e usado como recebido. Dodecil sulfato de sódio (grau de pureza: $29 \%$ ) foi adquirido da Rhodia e usado como recebido. Todos os demais produtos químicos usados foram em grau P.A. e usados como recebido.

\section{Síntese da magnetita modificada com ácido oleico}

A síntese da magnetita modificada com ácido oleico foi realizada de acordo com a literatura ${ }^{[12]}$.

Inicialmente, foram misturados as soluções dos sais de ferro II (14 g de $\mathrm{Fe}^{2+}$ em $50 \mathrm{~mL}$ de água destilada) e ferro III (27 g de $\mathrm{Fe}^{3+}$ em $50 \mathrm{~mL}$ de água destilada) em um becher de 2 litros e em seguida adicionou-se lentamente $130 \mathrm{~mL}$ de uma solução de $\mathrm{NaOH}$ concentrada, sob agitação magnética. Após a adição da base, o meio reacional passou de um tom castanho a preto e foi mantido aquecido a temperatura de $90{ }^{\circ} \mathrm{C}$ por 1 hora sob agitação. Passado o tempo requerido, adicionou-se um volume correspondente de ácido oleico $(10 \mathrm{~mL})$ e por último a mistura foi posta para resfriar por 24 horas.

O precipitado, magnetita modificada com ácido oleico, foi separado por decantação forçada por um campo magnético e lavado com água quente $\left(100^{\circ} \mathrm{C}\right)$ e etanol. A magnetita modificada foi para a estufa por 24 horas a $60{ }^{\circ} \mathrm{C}$ na forma de uma lama. Após secagem, foi triturada em gral e guardada sob a forma de pó na ausência de luz.

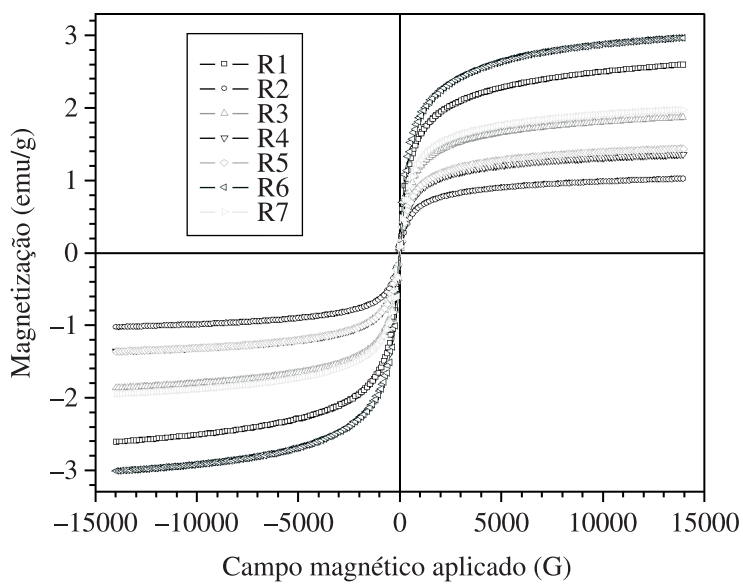

Figura 1. Curvas de magnetização dos copolímeros de poli(estirenoco-divinilbenzeno) sintetizados com $\mathrm{Fe}_{3} \mathrm{O}_{4} / \mathrm{AO}$. Condições reacionais constantes: $\mathrm{STY} / \mathrm{DVB}=95 / 5 ; \mathrm{T}=90{ }^{\circ} \mathrm{C} ; \mathrm{t}=4$ horas; $[\mathrm{PVA}]=0,5 \% \mathrm{p} / \mathrm{v}$; $\left[\mathrm{Fe}_{3} \mathrm{O}_{4}\right]=5 \mathrm{~g} ; \mathrm{R} 1-400 \mathrm{RPM} ;[\mathrm{BPO}]=1 \% ; \mathrm{R} 2-400 \mathrm{RPM} ;[\mathrm{BPO}]=3 \%$; $\mathrm{R} 3, \mathrm{R} 4$ e R5 - $600 \mathrm{RPM} ;[\mathrm{BPO}]=2 \% ; \mathrm{R} 6-800 \mathrm{RPM} ;[\mathrm{BPO}]=1 \%$; $\mathrm{R} 7-800 \mathrm{RPM} ;[\mathrm{BPO}]=3 \%$.

Tabela 1. Características das microesferas de poli(estireno-co-divinilbenzeno) sintetizadas com magnetita.

\begin{tabular}{cccccccccc}
\hline Resina & $\begin{array}{c}\text { Velocidade } \\
\text { de agitação } \\
(\mathbf{R P M})\end{array}$ & $\begin{array}{c}\text { Iniciador } \\
*(\boldsymbol{\%})\end{array}$ & $\begin{array}{c}\text { Rendimento } \\
\text { da reação }(\boldsymbol{\%})\end{array}$ & $\begin{array}{c}\text { Diâmetro } \\
\text { médio de } \\
\text { partícula }(\boldsymbol{\mu m})\end{array}$ & $\mathbf{F e}^{* * *}(\boldsymbol{\%})$ & $\mathbf{H}_{\mathbf{C}}(\mathbf{G})$ & $\mathbf{M}_{\mathbf{S}}(\mathbf{e m u} / \mathbf{g})$ & $\mathbf{M}_{\mathbf{R}}(\mathbf{e m u} / \mathbf{g})$ \\
\hline R1 & 400 & 1 & 91 & 162 & 2,8 & 35,35 & 2,60 & 0,15 \\
R2 & 400 & 3 & 87 & 183 & 1,3 & 35,71 & 1,02 & 0,05 \\
R3 & 600 & 2 & 87 & 245 & 2,1 & 47,34 & 1,86 & 0,13 \\
R4 & 600 & 2 & 77 & 577 & 2,6 & 39,96 & 1,36 & 0,08 \\
R5 & 600 & 2 & 84 & 223 & 1,6 & 39,63 & 1,40 & 0,08 \\
R6 & 800 & 1 & 89 & 81 & 3,3 & 45,49 & 2,99 & 0,21 \\
R7 & 800 & 3 & 91 & 207 & 2,6 & 50,95 & 1,96 & 0,15 \\
\hline
\end{tabular}

*Peróxido de benzoíla - \% em relação à soma dos números de mols dos monômeros; ** Determinado por espectrometria de absorção atômica com chamas; $H_{c}$ - Força coerciva; $M_{S}-$ Magnetização de saturação; $M_{R}-$ Magnetização remanescente; Condições reacionais mantidas constantes: STY/DVB = 95/5; $\mathrm{T}=90^{\circ} \mathrm{C} ; \mathrm{t}=4$ horas; $[\mathrm{PVA}]=0,5 \% \mathrm{p} / \mathrm{v} ;\left[\mathrm{Fe}_{3} \mathrm{O}_{4}\right]=5 \mathrm{~g}$. 


\section{Síntese dos núcleos de poli(estireno-co-divinilbenzeno) e magnetita}

Os copolímeros magnéticos foram sintetizados através da polimerização em suspensão aquosa. Preliminarmente, a fase orgânica, composta de estireno e DVB (95/5 em mols), 1 \% de BPO e $10 \%$ de magnetita ambos em relação ao número total de moles dos monômeros, foi submetida a um banho ultrassônico por 30 minutos. A fase aquosa (FA) foi formada com poli(álcool vinílico) $88 \%$ hidrolisado utilizado como agente de suspensão a $0,5 \%$ (p/p) em relação à água. A mistura fase aquosa/fase orgânica foi adicionada a um balão de três bocas de capacidade de $500 \mathrm{~mL}$ equipado com um dispersor e um borbulhador de nitrogênio, agitador mecânico e condensador de refluxo. A mistura reacional foi então aquecida a $90{ }^{\circ} \mathrm{C}$ em banho termostatizado, sob agitação por 4 horas.

\section{Formação da casca de poli(estireno-co-divinilbenzeno)}

A metodologia aplicada nesta etapa do trabalho foi adaptada da literatura ${ }^{[6]}$.

Os núcleos foram dispersos em uma solução de poli(álcool vinílico) (PVA) $(0,6 \%$ p/p). Obteve-se então, uma dispersão de núcleos com concentração de $0,1 \mathrm{~g} / \mathrm{mL}$. A dispersão foi adicionada a um balão de três bocas de $500 \mathrm{~mL}$ equipado com agitador mecânico. A mistura ficou sob agitação por 30 minutos a 500 RPM.

Paralelamente, foi preparada uma emulsão com álcool isoamílico (AI) $(5 \%$ p/p em relação à fase orgânica), dodecil-sulfato de sódio (DSS) $(0,25 \%$ p/p em relação à fase orgânica), tolueno (razão mássica tolueno/monômeros $=1 / 1$ ), monômeros (estireno/ divinilbenzeno $=65 / 35$ em mols) e iniciador a $1 \%$ molar (em relação aos monômeros). A emulsão foi devidamente vedada e colocada em banho ultrassônico por 30 minutos a temperatura ambiente.

A adição da emulsão a dispersão dos núcleos foi feita de três formas distintas. A primeira foi realizada em três etapas, lentamente e colocadas para inchar por 48 horas sob agitação de 500 RPM (resina RR48/1). A segunda consistiu na adição de uma única vez

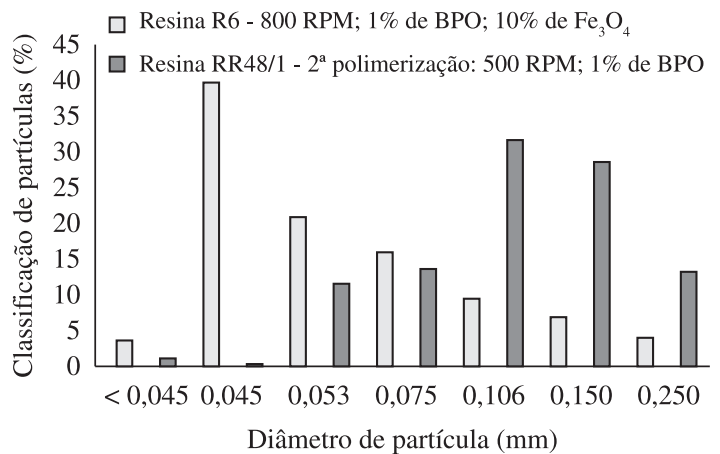

lentamente e inchadas por 48 horas sob agitação de 500 RPM (resina RR48/3). A terceira consistiu em adicionar a emulsão em duas etapas rapidamente e inchadas por 72 horas a 500 RPM (resina RR72).

Após a etapa do inchamento, as resinas foram polimerizadas a $500 \mathrm{RPM}$ com a $70{ }^{\circ} \mathrm{C}$ por 24 horas

\section{Purificação}

As microesferas resultantes das duas etapas foram separadas por filtração a pressão reduzida e lavadas exaustivamente com água destilada, água destilada quente e álcool etílico e secas em estufa com circulação forçada de ar, a $60{ }^{\circ} \mathrm{C}$, por 48 horas.

\section{Caracterização das microesferas poliméricas obtidas}

As amostras dos copolímeros, após a secagem, foram peneiradas em peneirador hidráulico (Peneirador Retsch, modelo AS 2000 basic).

A degradação térmica dos materiais foi verificada por TGA/DTGA (TA Instruments, modelo Q50 V6.4 Build 193), onde

Tabela 2. Características das resinas magnéticas com morfologia casca-núcleo.

\begin{tabular}{lccc}
\hline Resina & $\begin{array}{c}\text { Diâmetro } \\
\text { médio }(\mu \mathbf{m})\end{array}$ & $\begin{array}{c}\text { Massa de casca } \\
\text { incorporada ao } \\
\text { núcleo }(\mathbf{g})\end{array}$ & $\begin{array}{c}\text { Rendimento } \\
(\boldsymbol{\%})\end{array}$ \\
\hline R6 (núcleo) & 81 & - & - \\
RR 48/1 & 127 & 3,5 & 64 \\
RR 48/3 & 101 & 2,0 & 36 \\
RR 72 & 104 & 2,3 & 43 \\
\hline
\end{tabular}

RR 48/1 - Emulsão de STY/DVB adicionada em etapa única; 48 horas de inchamento a $10^{\circ} \mathrm{C}$; RR 48/3 - Emulsão de STY/DVB adicionada em três etapas; 48 horas de inchamento a $10^{\circ} \mathrm{C}$; RR 72 - Emulsão de STY/DVB adicionada em duas etapas; 72 horas de inchamento a $10{ }^{\circ} \mathrm{C}$; Condições reacionais mantidas constantes: Tempo de polimerização: 24 horas; $\mathrm{T}=70^{\circ} \mathrm{C} ; 500 \mathrm{RPM} ;[\mathrm{BPO}]=1 \%$.

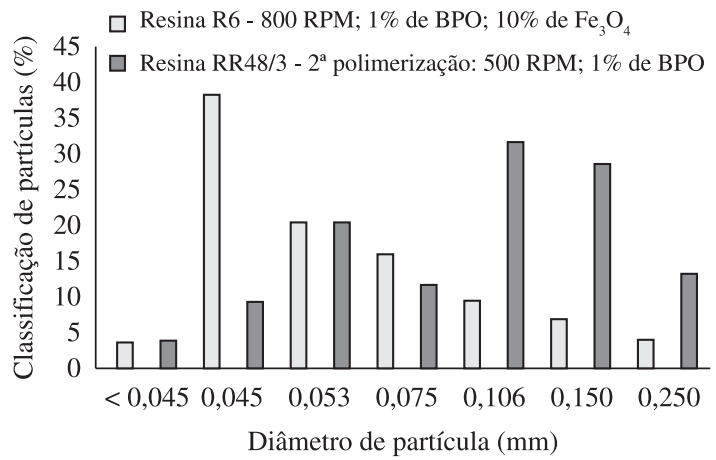

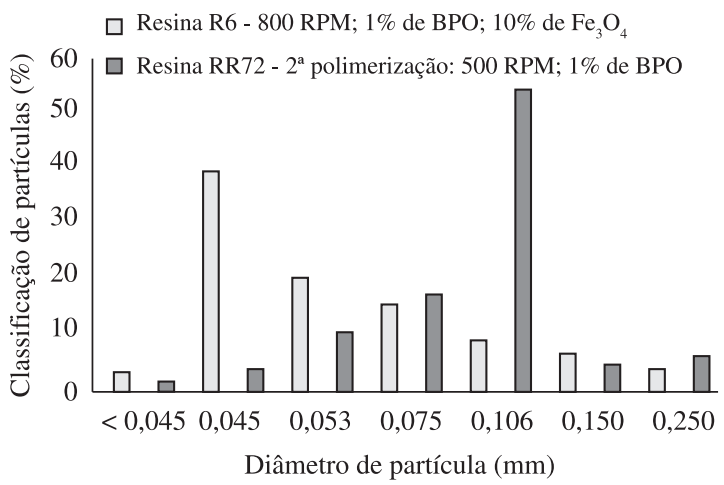

Figura 2. Curvas de distribuição de tamanho das partículas que compuseram o núcleo (R6) e das microesferas com morfologia casca e núcleo (RR 48/1, RR 48/3 e RR 72). R6 - Núcleo; RR 48/1 - Emulsão de STY/DVB adicionada em etapa única; 48 horas de inchamento a $10{ }^{\circ} \mathrm{C}$; RR 48/3 - Emulsão de STY/DVB adicionada em três etapas; 48 horas de inchamento a $10{ }^{\circ} \mathrm{C}$; RR 72 - Emulsão de STY/DVB adicionada em duas etapas; 72 horas de inchamento a $10{ }^{\circ} \mathrm{C}$; Condições reacionais mantidas constantes: Tempo de polimerização: 24 horas; $\mathrm{T}=70{ }^{\circ} \mathrm{C} ; 500 \mathrm{RPM} ;[\mathrm{BPO}]=1 \%$. 
cerca de $10 \mathrm{mg}$ de amostra foram colocadas em uma cápsula de platina que foi aquecida em atmosfera de nitrogênio com uma vazão de $100 \mathrm{~mL} / \mathrm{min}$, de $50{ }^{\circ} \mathrm{C}$ a $650{ }^{\circ} \mathrm{C}$ a uma velocidade de $10{ }^{\circ} \mathrm{C} / \mathrm{min}$. As características magnéticas dos copolímeros foram analisadas por magnetômetro de amostra vibrante (VSM) (Lake Shore, modelo Série 7400), onde cerca de 0,05 $\mathrm{g}$ de amostra foram adicionadas ao aparelho e o campo magnético aplicado variou de $-14000 \mathrm{G}$ a $14000 \mathrm{G}$ e o tempo total de cada análise foi de 10 minutos, sendo os dados coletados a cada segundo. A morfologia dos materiais foi analisada por SEM-EDS (Carl Zeiss do Brasil, modelo Leo $1450 \mathrm{VPO}$ ), onde as amostras foram revestidas por uma fina camada de ouro para aumentar sua condutividade e proteger contra o aquecimento localizado. A seguir, a amostra preparada interagiu com elétrons secundários, em alto vácuo, sob uma tensão de aceleração de $20 \mathrm{kV}$. Espectros de energia dispersiva de raios-X também foram adquiridos para confirmar a incorporação do ferro nos copolímeros. Por fim, a quantidade de ferro incorporado no núcleo foi determinada por espectrofotometria de absorção atômica (Perkin Elmer Analyst 300). Para isso, foram pesadas cerca de $0,0100 \mathrm{~g}$ de amostra e, em seguida, adicionadas $20 \mathrm{~mL}$ de solução de água régia $\left(\mathrm{HNO}_{3}: \mathrm{HCl}=1: 3\right.$ em volume $)$. Esta mistura foi aquecida na temperatura de refluxo por 24 horas. Depois de resfriada, a solução obtida foi filtrada, transferida para balão volumétrico de $100 \mathrm{~mL}$ e avolumado com água destilada e deionizada. Em seguida, uma alíquota foi analisada no espectrômetro de absorção atômica nas seguintes condições: $\lambda=248,3 \mathrm{~nm}$; largura da fenda do monocromador $(\mathrm{f})=0,2 \mathrm{~nm} ; \mathrm{i}=10 \mathrm{~mA}$ em chama de ar-acetileno e tempo de leitura $=3 \mathrm{~s}$. A concentração de ferro foi obtida diretamente da equação da curva de calibração.

\section{Resultados e Discussão}

Neste Trabalho, foram sintetizadas partículas de magnetita $\left(\mathrm{Fe}_{3} \mathrm{O}_{4}\right)$ pelo método de copreciptação e em seguida modificou-se sua superfície com ácido oleico (AO). A magnetita sintetizada apresentou magnetização de saturação (Ms) de 48,26 emu/g.

\section{Síntese do núcleo de poli(estireno-co-divinilbenzeno) com magnetita}

A fim de se determinar as condições reacionais mais apropriadas para a obtenção da resina que atuará como núcleo, foram realizadas reações de polimerização de estireno (STY) e divinilbenzeno (DVB), variando-se a velocidade de agitação e a concentração de iniciador (BPO) (Tabela 1). A resina mais adequada para constituir o núcleo das microesferas com morfologia casca e núcleo seria aquela que apresentasse o menor tamanho de partícula e o maior teor de material magnético incorporado.

A Tabela 1 mostra que as resinas apresentaram uma larga distribuição de tamanho, com o diâmetro médio situando-se entre 81 e $577 \mu \mathrm{m}$.

Os teores de ferro $\left(\mathrm{Fe}_{3} \mathrm{O}_{4} / \mathrm{AO}\right)$ incorporados nos copolímeros foram determinados por espectroscopia de absorção atômica e também são mostrados na Tabela 1.

O copolímero R6 além de apresentar o menor diâmetro médio de partícula, também apresentou o maior teor de ferro incorporado $(3,3 \%)$ e a maior magnetização de saturação $(\mathrm{Ms}=3,32 \mathrm{emu} / \mathrm{g})$ (Tabela 1). Os valores de magnetização remanescente $\left(M_{R}\right)$ ficaram próximos de zero, indicando que os copolímeros apresentaram propriedades próximas a de um material superparamagnético.

A curva de histerese das resinas (Figura 1) mostrou que as resinas apresentaram diferentes magnetizações de saturação. Além disso, pode-se observar que ambas as curvas não apresentaram ciclo de histerese, fenômeno que causa o atraso entre a densidade de fluxo magnético e o campo magnético ${ }^{[13-14]}$.
A literatura mostra que para um mesmo material magnético, quanto maior for a quantidade de ferro incorporado na matriz polimérica, maior será a sua magnetização de saturação $0^{[15]}$.

No presente trabalho, o teor de incorporação da magnetita nas resinas variou de 1,3 a 3,3\% e os níveis de magnetização de saturação (Ms) variaram entre 0,5 e $3 \mathrm{emu} / \mathrm{g}$. A resina R6 foi a resina que apresentou o maior teor de magnetita incorporado e, por conseguinte, teve a maior magnetização de saturação (Ms) (Tabela 1). Além disso, avaliando-se a distribuição de tamanho das partículas, a resina R6 obteve o menor diâmetro médio de partículas. Desta forma, a resina R6 (sintetizada com 1\% de iniciador e $800 \mathrm{rpm}$ ) foi a selecionada para ser o núcleo da resina com morfologia casca-núcleo.
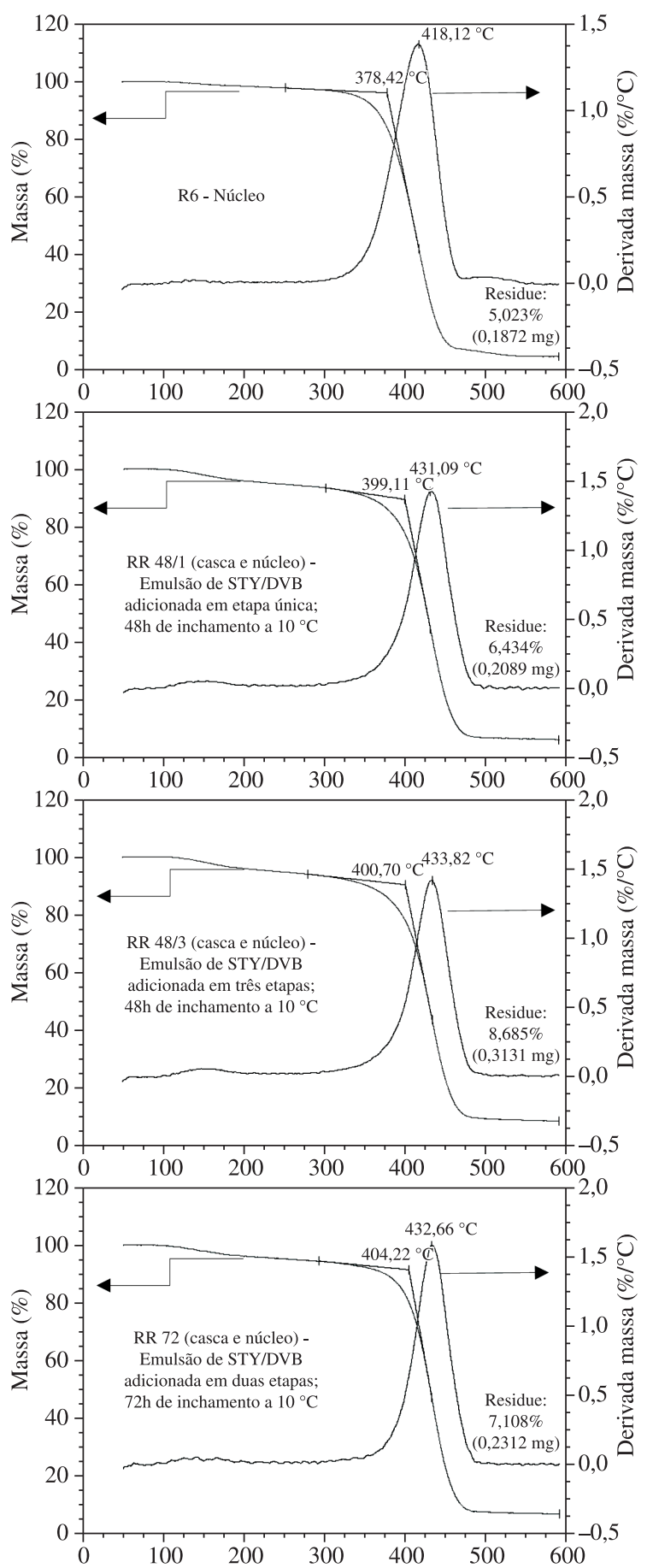

Figura 3. Curvas de TG/DTG do núcleo e das resinas casca e núcleo. 


\section{Síntese da casca de estireno e divinilbenzeno sem material magnético}

É importante ressaltar que nesta etapa foram analisados três métodos diferentes para a obtenção da casca. No primeiro, a emulsão dos monômeros da casca foi divida em três partes iguais e cada parte foi adicionada lentamente à dispersão dos núcleos com um intervalo de 1 hora entre elas, ficando a mistura final sob agitação a $10{ }^{\circ} \mathrm{C}$ por 48 horas. As resinas produzidas por este método foram denominadas RR 48/3.

No segundo método, a emulsão dos monômeros foi adicionada lentamente, porém de uma única vez, à dispersão dos núcleos, ficando a mistura final sob agitação a $10{ }^{\circ} \mathrm{C}$ por 48 horas. As resinas foram, então, denominadas RR 48/1.

O terceiro método consistiu em separar a emulsão dos monômeros em duas partes iguais e adicioná-las rapidamente com intervalo de 1 hora entre elas à dispersão de núcleos. Neste método, a mistura final foi mantida sob agitação a $10{ }^{\circ} \mathrm{C}$ por 72 horas e as resinas produzidas foram denominadas $\mathrm{RR} 72$.

A resina RR 48/1 foi a que apresentou o maior rendimento na polimerização (Tabela 2).

As faixas de distribuição de tamanho de partículas após a formação da casca sobre o núcleo foram determinadas a partir de separação granulométrica por peneiramento. Os resultados obtidos foram fundamentais para saber se houve a formação da casca. A distribuição de tamanho de partículas da resina R6 serviu como base para este estudo, em função destas terem sido escolhidas como núcleos. Desta forma, havendo a formação de uma casca sobre o núcleo, esperava-se um aumento no diâmetro médio da resina ao término da polimerização da casca.

Ao comparar as resinas R6 (núcleo) e RR 48/1 (Figura 2), pode-se observar que a curva referente à resina RR 48/1 deslocou-se para o lado direito do eixo, indicando e comprovando que houve um aumento no diâmetro destas. O diâmetro médio do núcleo (R6) foi $81 \mu \mathrm{m}$, já o da resina com a casca (RR48/1) foi $127 \mu \mathrm{m}$ (Tabela 2). A mesma tendência foi encontrada para as resinas RR 48/3 e RR 72.

A Figura 3 mostra as curvas de degradação térmica do núcleo e das resinas casca e núcleo. Como pode ser observado, todos os copolímeros sintetizados apresentaram uma pequena perda de massa $(<5 \%)$ entre 120 e $175^{\circ} \mathrm{C}$. Esta perda pode ser atribuída à perda de água. Acima de $175^{\circ} \mathrm{C}$ observou-se apenas um estágio de degradação indicando que não houve mudança no perfil de degradação de acordo com o método de formação da casca. A Figura 3 mostra também que as resinas RR 48/1, RR 48/3 e RR 72, obtidas após a formação da casca, apresentaram tendência a maiores valores de $\mathrm{T}_{\max }$ do que a resina que compõe o núcleo (R6). Provavelmente isso ocorreu em

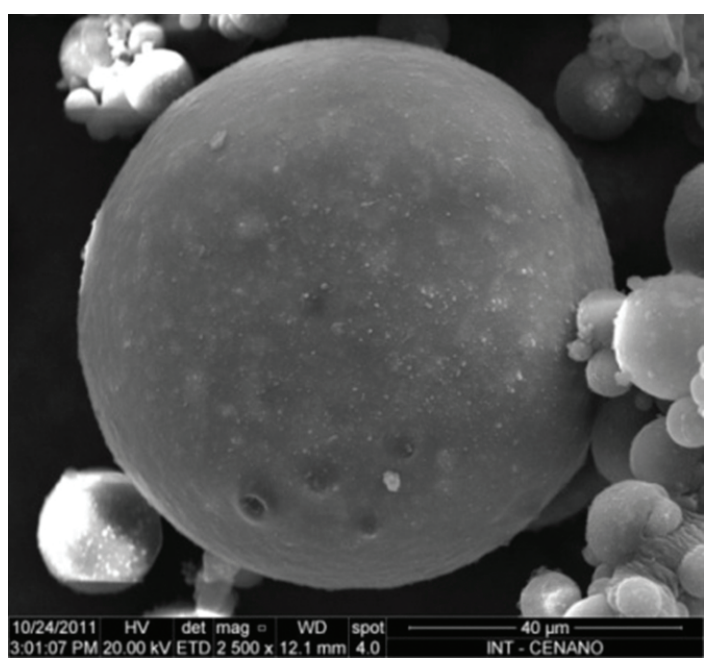

(a)

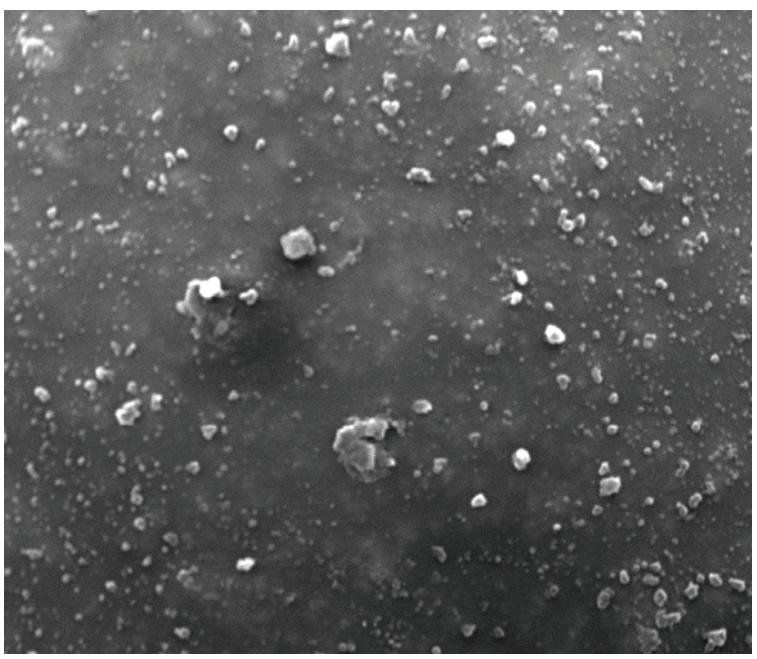

(b)

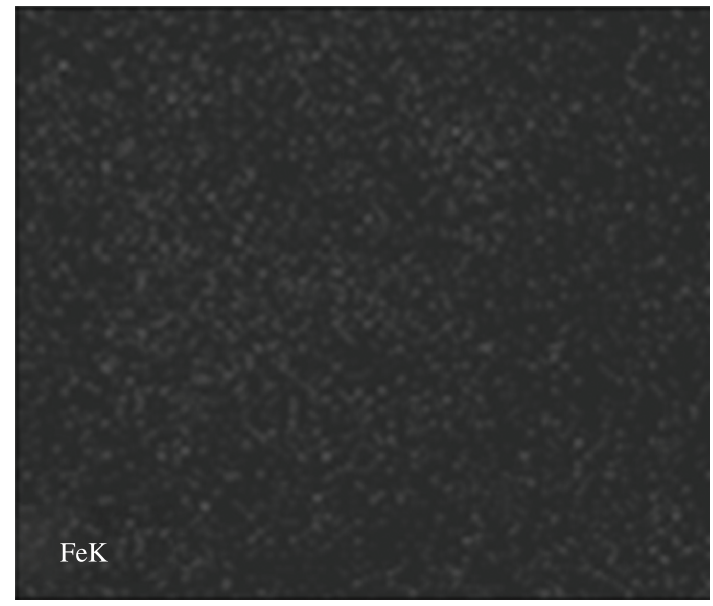

(c)

Figura 4. Micrografia de microscopia eletrônica de varredura do núcleo (R6) com aumento de 1.000× (a); da superfície do núcleo (b) e de seu mapa composicional de ferro (c). Ambos com aumento de 10 000x. 


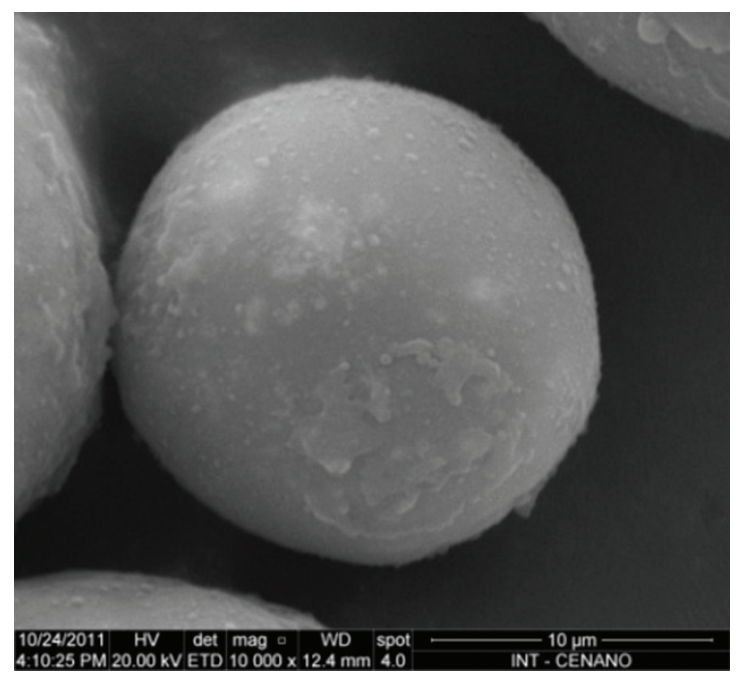

(a)

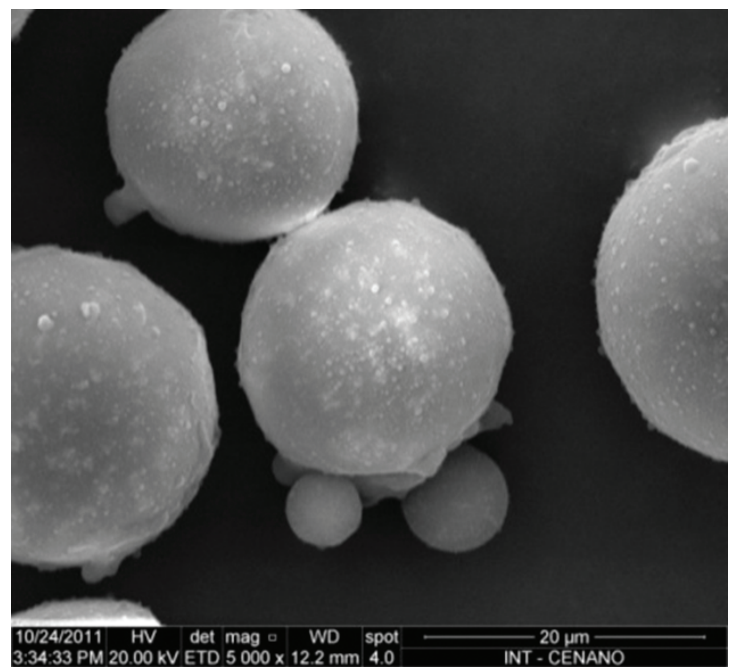

(b)

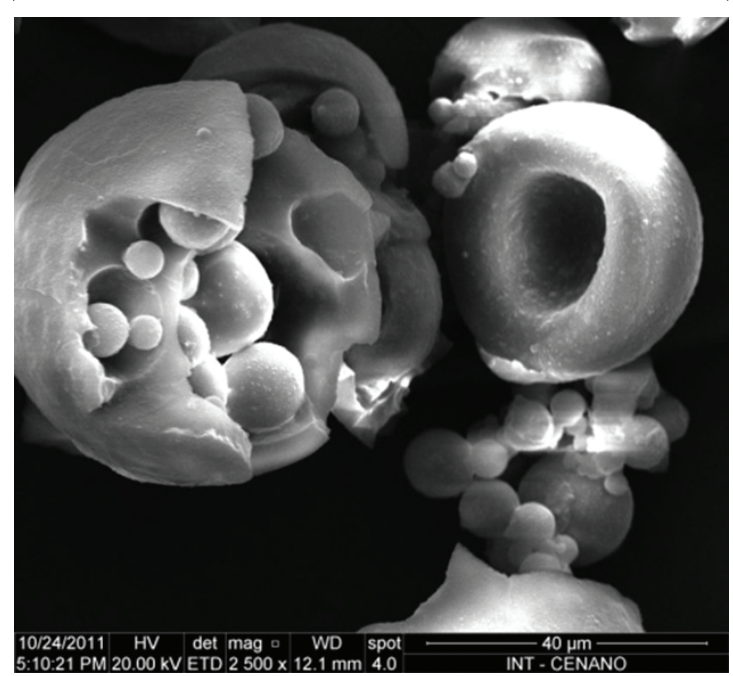

(c)

Figura 5. Micrografia de microscopia eletrônica de varredura das resinas casca-úcleo: (a) RR 48/1 (aumento: 10.000×); (b) RR 48/3 (aumento: 5 000×) e (c) RR 72 (aumento: 2 500x)

virtude da casca conter cerca de $35 \%$ de DVB, tornando assim, as resinas mais resistentes à degradação térmica quando comparadas ao núcleo isolado, que contém apenas $5 \%$ de DVB.

$\mathrm{O}$ aspecto morfológico das microesferas foi avaliado por microscopia eletrônica de varredura (MEV). A Figura 4a mostra a resina R6 que compõe o núcleo. É possível notar que existem agregados de partículas nanométricas sobre a superfície irregular da resina R6 (Figura 4b). Mediante seu mapa de composição de ferro (Figura 4c), constatou-se que as partículas presentes na superfície da microesfera são provavelmente de magnetita.

Após a formação da casca, as resinas RR 48/1 e RR 48/3 mantiveram a sua morfologia esférica, conforme pode ser observado nas Figuras 5a, b, respectivamente. Entretanto, o mesmo não foi observado para a resina RR 72 (Figura 5c). A má formação da casca pode ser explicada pelo fato da RR 72 ter ficado, durante a etapa de inchamento do núcleo, sob forte agitação mecânica por um intervalo de tempo superior às demais resinas.

A Figura 6 mostra o mapa de composição de ferro para a resina casca e núcleo RR 48/3. Como pode ser observado, há a presença de ferro na superfície da casca. Provavelmente, parte do material magnético da superfície do núcleo (Figura 4b) se desprendeu na

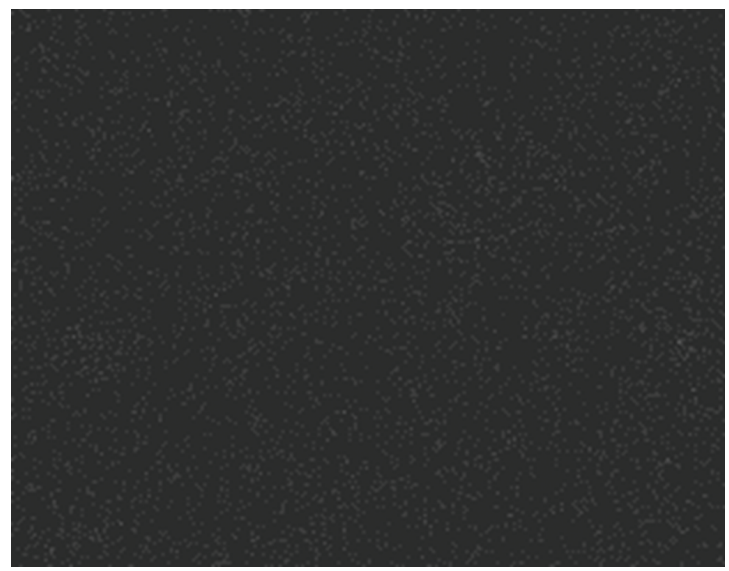

Figura 6. Mapa de composição de ferro da resina casca e núcleo RR 48/3.

etapa de inchamento, migrando assim para a emulsão que deu origem a casca.

A Figura 7 mostra os espectros de energia dispersiva de raios- $\mathrm{X}$ (EDS) do núcleo e das resinas casca-núcleo. Comparando-se o teor 


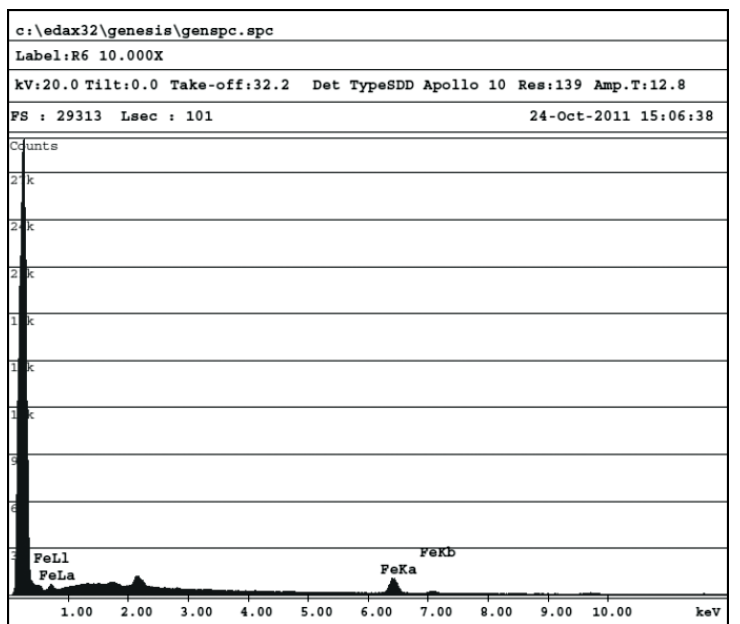

(a)

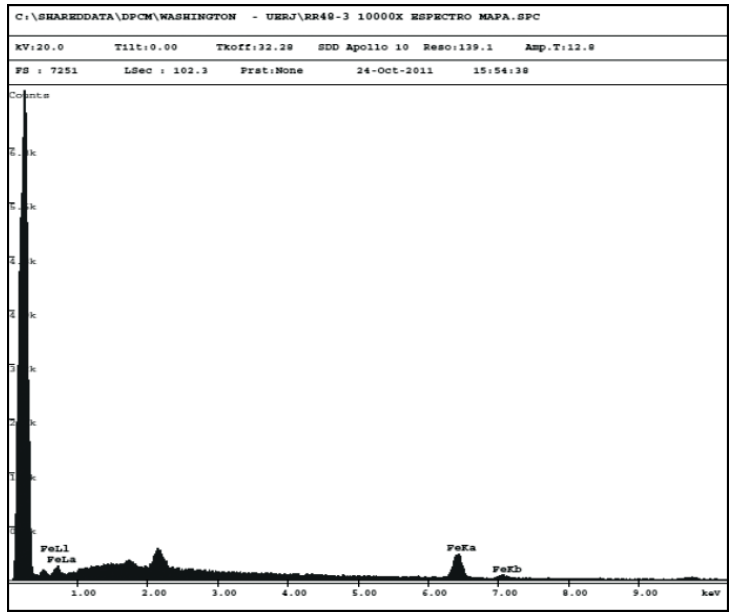

(c)

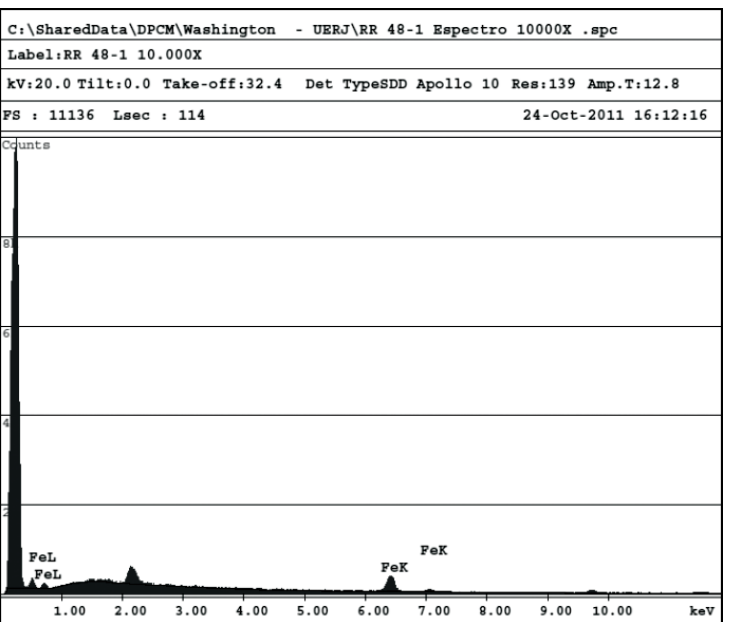

(b)

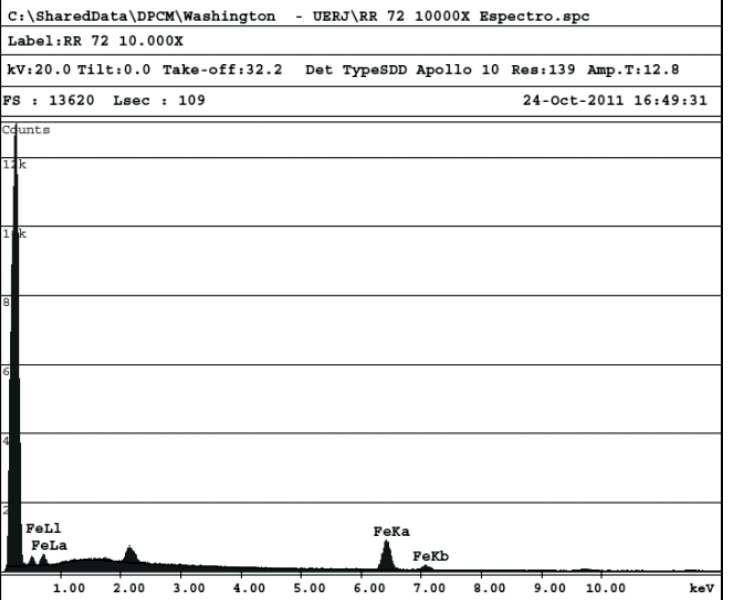

(d)

Figura 7. Espectro EDS do núcleo (a) e das resinas: RR 48/1 (b); RR 48/3 (c); RR 72 (d).

de ferro encontrado na superfície de ambas as resinas, verificou-se que a contagem de ferro para a resina do núcleo (Figura 7a) foi maior do que a contagem das resinas casca-núcleo.

Comparando-se somente as resinas casca-núcleo, é possível notar que a resina RR 72 (Figura 7d) foi a que apresentou o maior teor de ferro. Provavelmente isso ocorreu em virtude de esta resina ter apresentado a formação de novas microesferas no lugar de recobrir o núcleo (Figura 5c). Isso fez com que os núcleos não fossem cobertos integralmente pela casca, ficando assim, com parte de sua superfície exposta, originando uma contagem maior de ferro.

Diante dos resultados mostrados neste trabalho, pode-se concluir que a melhor resina com morfologia casca-núcleo foi a RR 48/1, em função de ter apresentado morfologia esférica, maior teor de casca e, por conseguinte, um maior diâmetro médio quando comparado com as outras resinas (RR 48/3 e RR 72). Além disso, embora a RR 48/1 não tenha apresentado um maior teor de ferro quando comparada à RR 72, esta não apresentou morfologia esférica.

\section{Conclusões}

Os três métodos avaliados na formação da casca de poli(estirenoco-divinilbenzeno) produziram partículas com diâmetro médio maior do que o núcleo. Este resultado é uma indicação da formação de morfologia casca e núcleo. O controle morfológico só foi obtido com as resinas RR48/1 e RR48/3, sendo que o método onde a emulsão de estireno e divinilbenzeno foi adicionada em etapa única, seguida de 48 horas de inchamento do núcleo a $10{ }^{\circ} \mathrm{C}$ (RR48/1) forneceu o maior rendimento $(64 \%)$. O método não influenciou a estabilidade térmica das partículas. Além disso, todas as resinas casca-núcleo foram sensíveis ao estímulo magnético realizado por um ímã, atestando assim que foram produzidas resinas com propriedades magnéticas.

\section{Agradecimentos}

Os autores agradecem à CAPES e à FAPERJ pelo apoio financeiro.

\section{Referências Bibliográficas}

1. Machado, F.; Lima, E. L. \& Pinto, J. C. Polímeros, 17, p.166 (2007). http://dx.doi.org/10.1590/S0104-14282007000200016

2. Daigle, J. C. \& Claverie, J. P. A. - J. Nanomater., 2008, p.1 (2008). http://dx.doi.org/ 10.1155/2008/609184

3. Zhenqian, Z., Yongzhong, B.; Zhiming, H. \& Zhixue, W. J. - Appl Polym. Sci., 111, p.1659 (2009). http://dx.doi.org/10.1002/app.28934

4. Philippova, O.; Barabanova, A.; Molchanov, V. \& Khokhlov, A. - Eur. Polym. J., 47, p.542 (2011). http://dx.doi.org/10.1016/j. eurpolymj.2010.11.006

5. Gonçalves, O. H., Machado, R. A. F., Araújo, P. H. M. \& Asua, J. M. - Macromolecules, 41, p.6960 (2008). 
6. Neves, M. A. F. S. - "Resinas de estireno-divinilbenzeno para cromatografia de exclusão por tamanho", Tese de Doutorado, Universidade Federal do Rio de Janeiro, Brasil (2001).

7. Liu, Z. L.; Yang, X. B.; Yao, K. L.; Du, G. H. \& Liu, Z. S. - J. Magn. Magn. Mater., 302, p.529 (2006). http://dx.doi.org/10.1016/j. jmmm.2005.10.223

8. Fu, G. D.; Li, G. L.; Neoh, K. G. \& Kang E. T. - Prog. Polym. Sci., 36, p.127 (2011). http://dx.doi.org/10.1016/j.progpolymsci.2010.07.011

9. Gervald, A. Y.; Gritskova, I. A. \& Prokopov, N. I. - Russian Chem. Rev., 79, p.219 (2010). http://dx.doi.org/10.1070/ RC2010v079n03ABEH004068

10. Martins, M. A.; Neves, M. C.; Esteves, A. C. C.; Girginova, P. I.; Guiomar, A. J.; Amaral, V. S. \& Trindade, T. - Nanotechnology, 18, p.215609 (2007). http://dx.doi.org/10.1088/0957-4484/18/21/215609

11. Furusawa, K.; Nagashima, K. \& Anzai, C. - Colloid \& Polym. Sci., 272, p.1104 (1994). http://dx.doi.org/10.1007/BF00652379
12. Neves, J. S.; Suarez, P. A. Z.; Umpierre, A. P. \& Machado, F. - Macromol. Mater. Eng., 296, p.1107 (2011). http://dx.doi. org/10.1002/mame.201100050

13. Costa, C. N.; Costa, M. A. S.; Santa-Maria, L. C.; Silva, M. R.; Souza Junior, F. G. \& Michel, R. C. - Polímeros, 21, p.260 (2011). http:// dx.doi.org/10.1590/S0104-14282012005000042

14. Costa, C. N. - "Síntese e Caracterização de copolímeros à base de poli(metacrilato de metila) e divinilbenzeno com propriedades magnéticas", Dissertação de Mestrado, Universidade do Estado do Rio de Janeiro, Brasil (2010).

15. Chung, T.; Pan, H. \& Lee, W. - J. Magn. Magn. Mater., 311, p.36 (2007). http://dx.doi.org/10.1016/j.jmmm.2006.11.165

Enviado: 02/02/12

Reenviado: $29 / 05 / 12$

Aceito: $25 / 06 / 12$ 